\title{
SENAM HIPERTENSI DAN DEMONSTRASI PEMBUATAN JUS \\ SELEDRI UNTUK PENDERITA HIPERTENSI DI PUCANG SAWIT SURAKARTA
}

\author{
Eska Dwi Prajayanti ${ }^{1}$, Irma Mustika Sari ${ }^{2}$, Tri Susilowati ${ }^{3}$ \\ Universitas'Aisyiyah Surakarta, Universitas 'Aisyiyah SurakartaE-mail : \\ eska_ners2012@yahoo.com
}

\begin{abstract}
Background : A health problem often faced by the elderly is hypertension. Hypertension is a cardiovascular degenerative symptom that is most commonly experienced by the elderly and cannot be known with certainty the cause. Management of hypertension in the elderly in addition to pharmacology can also be done with non-pharmacological exercises such as hypertension and eating celery juice. This study aims to determine the effect of celery juice and hypertension exercise on blood pressure in patients with hypertension in the Pucang Sawit region, Surakarta. Method of Implementation : lecture and demonstration. Conclusion : Hypertension and eating celery juice is an effort to control blood pressure in the elderly.
\end{abstract}

Keywords : Hypertension, elderly, blood pressure

\section{PENDAHULUAN}

Hipertensi merupakan salah satu penyebab kematian dini diseluruh dunia sehingga disebut sebagai "silent killer", karena seringkali penderita Hipertensi tidak merasakan gejala apapun. Hipertensi adalah suatu gangguan sistem dalam peredaran darah yang mengakibatkan kenaikan tekanan darah di atas rentang nilai normal, yaitu lebih dari 140/90 mmHg. Berdasarkan beberapa faktor penyebabnya, hipertensi dibagi menjadi 2 yaitu hipertensi primer dan hipertensi sekunder. Hipertensi primer merupakan suatu kondisi yang ditandai dengan tidak ditemukannya penyebab sekunder dari hipertensi. Sedangkan penyebab sekunder dari hipertensi yaitu seperti gagal ginjal, pheochromocytoma, aldosteronism, penyakit renovaskuler, dan berbagai macam penyakit lainnya (Triyanto, 2014).

World Health Organization (WHO) pada tahun 2012 mencatat setidaknya terdapat 839 juta kasus hipertensi, kasus hipertensi diperkirakan akan mengalami peningkatan menjadi 1,15 milyar penderita hipertensi pada tahun 2025 atau sekitar 29\% dari total keseluruhan penduduk di dunia, dan penderitanya lebih banyak pada wanita 
(30\%) dibandingkan pada pria (25\%). Sekitar $80 \%$ penderita kasus hipertensi mengalami kenaikan terutama di negara-negara berkembang (Triyanto, 2014). Sedangkan berdasarkan data yang diperoleh dari Riset Kesehatan Dasar pada tahun 2013, prevalensi penderita hipertensi di Indonesia mengalami penurunan dari 31,7\% pada tahun 2007 menjadi 25,8\% pada tahun 2013. Provinsi dengan prevalensi terendah berada di provinsi Papua $(16,8 \%)$ dan yang tertinggi berada di provinsi Bangka Belitung (30,9\%). Di Provinsi Jawa Tengah sendiri, berdasarkan pengukuran tekanan darah dinyatakan $26,4 \%$ pasien mengalami hipertensi (Riskesdas, 2013).

Penyakit hipertensi disederhanakan dengan sebutan tekanan darah tinggi level 140 $\mathrm{mmHg}$ atau lebih dan tekanan darah diastolik pada level $90 \mathrm{mmHg}$ atau lebih (Black \& Hawk, 2014). Hipertensi dapat memberikan kontribusi bagi kejadian penyakit jantung, gagal ginjal, stroke, kematian prematur dan cacat. Faktor pemicu terjadinya hipertensi diantaranya adalah faktor genetik, jenis kelamin, usia, tingkat stres, obesitas, dan konsumsi garam serta alkohol. Hipertensi merupakan faktor yang meningkatkan resiko terjadinya penyakit kardiovaskuler, gagal ginjal, stroke dan kematian. Melihat kompleknya permasalahan tekanan darah tinggi atau hipertensi, dapat disimpulkan bahwa apabila tidak dilakukan pengobatan dan pengontrolan tekanan darah maka akan dapat menimbulkan komplikasi pada tubuh (Suidah, 2011).

Upaya yang dapat dilakukan untuk menurunkan angka kejadian hipertensi diantaranya melakukan kegiatan pengukuran tekanan darah atau pemeriksaan kesehatan, penyuluhan mengenai penyakit hipertensi, pengobatan, serta penanganan untuk menurunkan tekanan darah. Upaya lain yang dapat dilakukan untuk mencegah hipertensi antara lain monitoring tekanan darah secara teratur, diet sehat dengan kalori yang seimbang melalui konsumsi tinggi serat, rendah lemak dan rendah garam, serta program hidup sehat tanpa asap rokok.

Salah satu bentuk kegiatan yang dapat dilakukan oleh tenaga kesehatan adalah untuk pengontrolan tekanan darah dengan memberikan pendidikan kesehatan kepada penderita hipertensi (Susanti, et al. 2012).

Pendidikan kesehatan merupakan suatu proses yang direncanakan untuk mempengaruhi atau mengajak orang lain, baik individu, kelompok atau masyarakat agar melaksanakan perilaku hidup sehat (Nursalam \& Efendi, 2008). Hal ini sejalan dengan hasil penelitian Susanti, et al (2012) dimana ada pengaruh antara pendidikan kesehatan tentang hipertensi terhadap sikap dalam mengelola hipertensi. 
Salah satu tindakan nonfarmakologi yang dapat dilakukan untuk menurunkan tekanan darah pada penderita hipertensi adalah jus daun seledri. Hal ini sesuai dengan penelitian Pratiwi, et al (2019) dimana berdasarkan hasil penelitian, bagian dari daun seledri mengandung senyawa aktif yaitu "apigenin". Zat tersebut mampu menurunkan tekanan darah yang mekanisme kerjanya mirip dengan angiotensin dan mannitol yang berfungsi sebagai zat anti diuretik. Bagian batang dan daun seledri juga memiliki kandungan nitrat yang merupakan senyawa anti hipertensi.

Oleh karena itu, pengabdian masyarakat ini dilaksanakan untuk meningkatkan pengetahuan pada masyarakat yang beresiko mengalami hipertensi dam cara untuk mencegah terjadinya penyakit hipertensi.

\section{MASALAH, TARGET, DAN LUARAN}

Beberapa permasalahan yang ditemukan salah satunya adalah kurangnya pengetahuan mengenai penyakit hipertensi karena masyarakat belum pernah mendapatkan informasi tentang penanganan hipertensi dan lebih banyak bergantung pada obat-obatan. Pemanfaatan tindakan non farmakologi yang memiliki nilai ekonomi yang rendah dan efek samping yang sangat minimal juga belum banyak dilakuan di wilayah tersebut.
Target luaran yang dituju pada kegiatan pengabdian masyarakat adalah lansia yang mengalami hipertensi di daerah Belik Jambe RT 02 RW XI, Pucang Sawit, Surakarta. peningkatan kesadaran, pengetahuan, maupun perilaku lansia dalam hidup sehat mengenai penyakit hipertensi sehingga lansia menyadari pentingnya menjaga tekanan darah yang dialami saat ini Lansia akan diberi pendidikan kesehatan terkait penyakit hipertensi, pemeriksaan tekanan darah, diajarkan senam hipertensi, dan diberi pemahaman tentang pembuatan jus seledri dan mentimun untuk mengontrol hipertensi.

Luaran yang dihasilkan berupa akan dibuatkan buku saku yang akan dibagikan kepada masyarakat setempat dalam bentu booklet yang berisi tentang beberapa alternative tindakan untuk menurunkan tekanan darah tanpa menggunakan obat-obatan.

\section{METODE PELAKSANAAN}

Metode yang digunakan agar tercapai tujuan dari usulan pengabdian masyarakat ini adalah :

a. Pemberian materi yang akan disampaikan dengan menggunakan media visual sehingga memudahkan peserta untuk memahami dan mengikuti pesan yang disampaikan 
b. Ceramah sebagai metode komunikasi searah dan diskusi atau tanya jawab sebagai metode komunikasi dua arah

c. Demonstrasi cara pembuatan jus seledri serta senam khusus selama menjalani proses hipertensi

d. Pemberian dorprice yang berisi tentang metode penghitungan cairan serta penjelasan tentang asupan nutrisi sesuai tingkat keparahan penyakit.

\section{HASIL DAN PEMBAHASAN}

\section{A. HASIL KEGIATAN}

Data Demografi Responden dapat dilihat pada tabel berikut ini :

Tabel 1. Distribusi frekuensi Data

Demografi Lansia

\begin{tabular}{llll}
\hline No. & \multicolumn{1}{c}{ Karakteristik } & F & P(\%) \\
\hline 1. & Umur (tahun) & & \\
& a. 45-59 (middle age) & 29 & $41,42 \%$ \\
& b. 60-74 (elderly) & 41 & $58,58 \%$
\end{tabular}

2. Jenis Kelamin
a. Laki-laki
$27 \quad 38,57 \%$
b. Perempuan
$43 \quad 61,43 \%$

Berdasarkan karakteristik tabel 1 diperoleh gambaran mayoritas responden berusia 60-70 tahun sebanyak 41 responden $(58,58 \%)$ dan sebagian besar berjenis kelamin perempuan sebanyak 43 responden $(61,43 \%)$.

Data Distribusi Frekuensi Tekanan Darah

Tabel 2. Distribusi Frekuensi tekanan darah (n)

\begin{tabular}{lcc}
\hline \multicolumn{1}{c}{$\begin{array}{c}\text { Kategori Tekanan } \\
\text { Darah }\end{array}$} & $\begin{array}{c}\text { Jumlah } \\
(\mathbf{n})\end{array}$ & $\begin{array}{c}\text { Presentase } \\
(\boldsymbol{\%})\end{array}$ \\
\hline $\begin{array}{l}\text { Normal } \\
(<120 \mathrm{mmHg})\end{array}$ & 12 & $17,14 \%$ \\
\hline $\begin{array}{l}\text { Prehipertensi } \\
(120-139 \mathrm{mmHg})\end{array}$ & 23 & $32,86 \%$ \\
\hline $\begin{array}{l}\text { Hipertensi Primer } \\
\text { Stage } 1\end{array}$ & 35 & $50 \%$ \\
$(140-159 \mathrm{mmHg})$ & & \\
\hline Jumlah & 70 & $100 \%$ \\
\hline
\end{tabular}

Berdasarkan kategori tekanan darah pada tabel 2.diperoleh gambaran mayoritas responden mengalami hipertensi primer stage 1 sebanyak 35 responden (50\%), yang mengalami prehipertensi sebanyak 23 responden $(32,86 \%)$, dan untuk kategori tekanan darah normal sebanyak 12 responden $(17,14 \%)$. 
Tabel 3. Hasil Pengukuran Tekanan Darah Pada Lansia dengan Hipertensi

\begin{tabular}{|c|c|c|c|c|}
\hline \multirow{2}{*}{ Kategori Tekanan Darah } & \multirow{2}{*}{$\begin{array}{c}\text { Jumlah } \\
\text { (n) }\end{array}$} & \multirow{2}{*}{$\begin{array}{c}\text { Presentase } \\
(\%)\end{array}$} & \multicolumn{2}{|c|}{ Rerata Hasil Pengukuran } \\
\hline & & & Sebelum (mmHg) & Sesudah $(\mathrm{mmHg})$ \\
\hline $\begin{array}{c}\text { Normal } \\
(<120 \mathrm{mmHg})\end{array}$ & 12 & $17,14 \%$ & $120 / 90$ & $110 / 80$ \\
\hline $\begin{array}{c}\text { Prehipertensi } \\
\text { ( 120-139 mmHg) }\end{array}$ & 23 & $32,86 \%$ & $130 / 80$ & $120 / 80$ \\
\hline $\begin{array}{l}\text { Hipertensi Primer Stage } 1 \\
\quad(140-159 \mathrm{mmHg})\end{array}$ & 35 & $50 \%$ & $150 / 90$ & $140 / 80$ \\
\hline
\end{tabular}

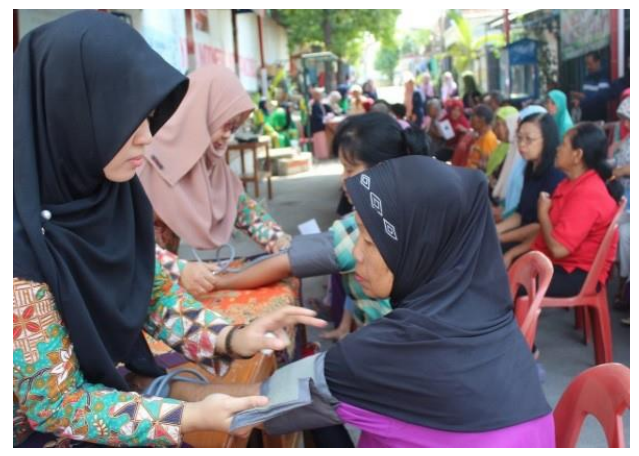

Gambar 1. Dokumentasi Tensi Gratis

Tabel 4. Karakteristik Responden

Berdasarkan Konsumsi Makanan Asin
Sebagian besar responden mengonsumsi makanan asin secara berlebih yaitu sebanyak 47 responden $(67,14 \%)$. Garam mengandung 40\% sodium dan $60 \%$ klorida, garam juga mempunyai sifat menahan air. Mengonsumsi garam yang berlebih atau makanan yang diasinkan dapat menaikkan tekanan darah.

\begin{tabular}{ccc}
\hline $\begin{array}{c}\text { Konsumsi } \\
\text { Makanan Asin }\end{array}$ & N & P (\%) \\
\hline Sedikit & 23 & $32,86 \%$ \\
Banyak & 47 & $67,14 \%$ \\
\hline Total & $\mathbf{7 0}$ & $\mathbf{1 0 0 \%}$ \\
\hline
\end{tabular}

Tabel 5. Tingkat Pengetahuan Responden

\begin{tabular}{llllll}
\hline \multirow{2}{*}{ No } & \multirow{2}{*}{ Kriteria } & \multicolumn{4}{c}{ Pengetahuan } \\
\cline { 3 - 6 } & & Sebelum & Presentase (\%) & Sesudah & Presentase (\%) \\
\hline 1. & Rendah & 40 & $57,14 \%$ & 5 & $7,14 \%$ \\
2. & Sedang & 20 & $28,57 \%$ & 10 & $14,29 \%$ \\
3. & Tinggi & 10 & $14,29 \%$ & 55 & $78,57 \%$ \\
\hline \multicolumn{2}{l}{ Total } & $\mathbf{7 0}$ & $\mathbf{1 0 0 \%}$ & $\mathbf{7 0}$ & $\mathbf{1 0 0 \%}$ \\
\hline
\end{tabular}


Berdasarkan kategori pengetahuan pada tabel 5. Diperoleh gambaran bahwa sebelum diberikan pendidikan kesehatan mayoritas responden pengetahuan tentang penyakit hipertensi masih sangat rendah yaitu sebasar $57,14 \%$ dan setelah diberikan pendidikan kesehatan mayoritas responden pengetahuannya meningkat sebesar $78,57 \%$.

\section{Penyuluhan Kesehatan}

Kegiatan penyuluhan kesehatan terlaksana dengan baik. Kegiatan ini diikuti oleh 70 orang lansia. Hasil dari kegiatan ini lansia mampu memahami tentang hipertensi mulai dari definisi, etiologi, manifestasi klinis, komplikasi, pencegahan dan penatalaksanaan untuk menurunkan tekanan darah dari penderita hipertensi dengan baik dan benar baik penatalaksanaan farmakologi maupun non farmakologi.

Saat kegiatan pendidikan kesehatan berlangsung, moderator dapat menciptakan suasana yang kondusif. Alur kegiatan pendidikan kesehatan ini dimulai dari penyampaian materi mengenai "Hipertensi" oleh Ibu Irma Mustika Sari dan Ibu Eska Dwi Prajayanti, kemudian moderator membuka 1 termin dengan 3 orang penanya. Dalam sesi tanya jawab ini Bapak Kris, Ibu Dwi Sujiati, Bapak RT melontarkan beberapa pertanyaan mengenai hipertensi. Semua pertanyaan yang telah diajukan peserta dijawab oleh Dosen Universitas 'Aisyiyah Surakarta. Tidak hanya peserta yang melontarkan beberapa pertanyaan, penyaji pun juga melontarkan beberapa pertanyaan kepada peserta sebagai umpan balik dari kegiatan ini. Saat penyaji melontarkan pertanyaan, $70 \%$ peserta dapat menjawab pertanyaan dengan tepat.

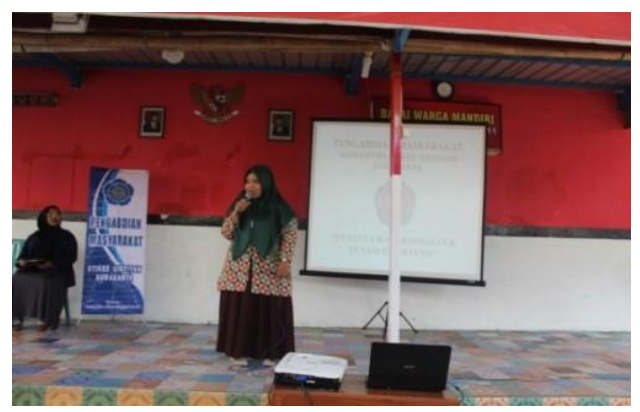

Gambar 2.

Dokumentasi Penyampaian materi

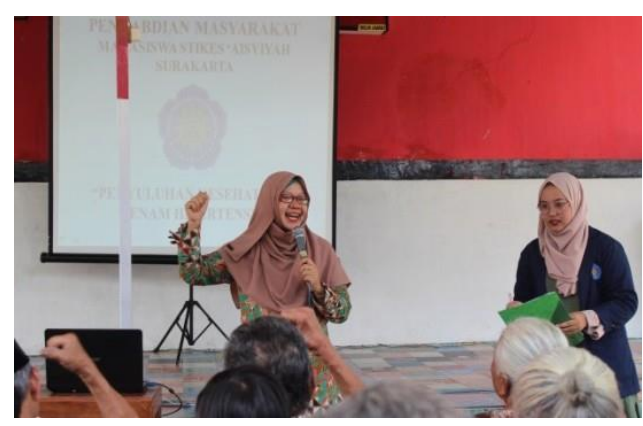

Gambar 3.

Dokumentasi Sesi Tanya Jawab 


\section{Senam Hipertensi}

Kegiatan senam hipertensi terlaksana dengan baik. Hasil dari kegiatan ini adalah lansia mampu menerapkan gerakan-gerakan senam saat di rumah sebagai salah satu cara untuk menurunkan hipertensi.

Kegiatan ini diikuti oleh 70 orang lansia. Alur kegiatan ini dimulai dengan gerakan pemanasan, senam hipertensi, dan yang terakhir pendinginan.Senam hipertensi ini dilakukan selama 30 menit. Kegiatan ini dipandu oleh 1 orang instruktur yaitu Mahasiswi Universitas 'Aisyiyah Surakarta. Dalam kegiatan ini tidak mengharuskan lansia senam dengan posisi berdiri, tetapi lansia juga dapat melakukan senam dengan posisi duduk.

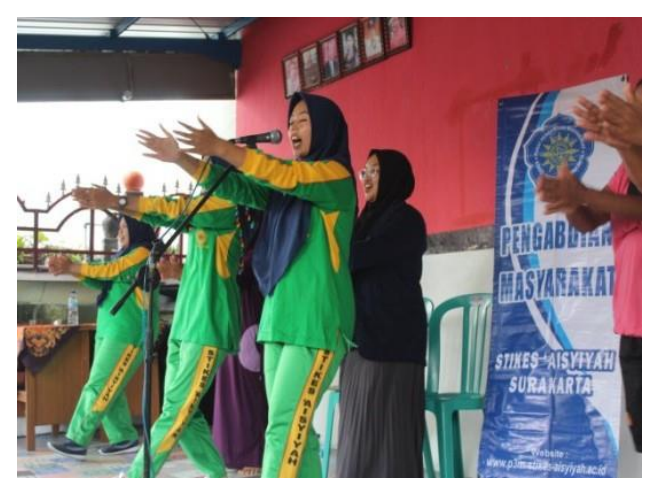

Gambar 4.

Dokumentasi Instruktur Senam

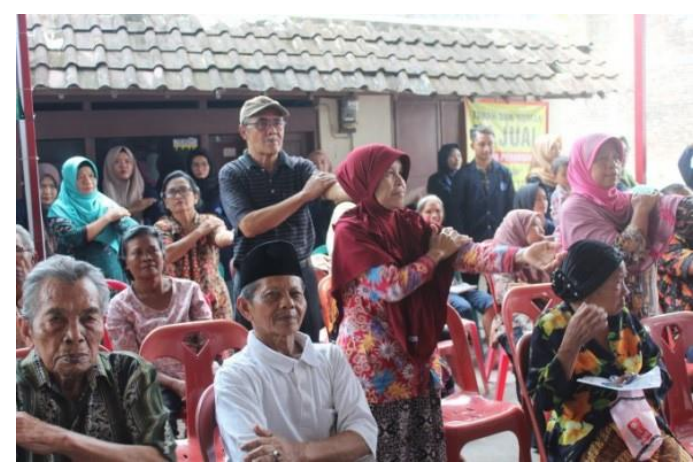

Gambar 5.

Dokumentasi Senam Hipertensi

\section{Demonstrasi Pembuatan Jus Seledri} dan Mentimun

Demonstrasi pembuatan jus seledri dan mentimu ini terlaksana dengan baik. Hasil dari kegiatan ini adalah lansia mampu mengetahui bagaimana cara membuat jus daun seledri dan mentimun sebagai salah satu cara untuk menurunkan hipertensi.

Kegiatan ini diikuti oleh 70 orang lansia. Alur kegiatan ini dimulai dengan penjelasan tentang manfaat serta kandungan jus daun seledri dan mentimun, kemudian pendemonstrasian pembuatan jus, dan yang terakhir pembagian jus untuk lansia. Kegiatan ini dilakukan selama 20 menit. Pembuatan jus ini didemonstrasikan oleh 2 Mahasiswi Universitas 'Aisyiyah Surakarta. 


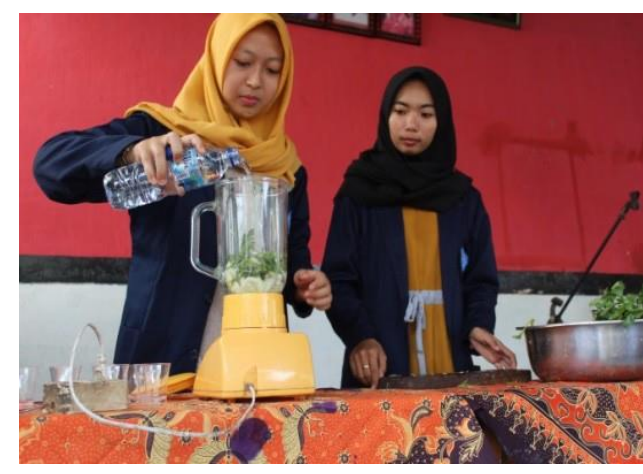

Gambar 6. Demonstrasi Pembuatan Jus Seledri \& Timun

\section{B. PEMBAHASAN}

Hasil dari kegiatan yang dilakukan di Balai warga RT 02 RW XI, Belik Jambe, Pucang Sawit, Surakarta didapatkan bahwa 58,58\% yang mengalami hipertensi adalah usia 60-74 tahun. Faktor usia sangat berpengaruh terhadap hipertensi karena dengan bertambahnya umur maka semakin tinggi mendapat risiko hipertensi. Kejadian hipertensi makin meningkat dengan bertambahnya usia. Hal ini sering disebabkan oleh perubahan alamiah di tubuh yang mempengauhi jantung, pembuluh darah, dan hormon. Hipertensi pada usia kurang dai 35 tahun akan menaikkan insiden penyakit arteri koroner dan kematian prematur (Suhadak, 2010). Hal ini sesuai dengan data di lapangan kebanyakan responden lansia yang mengalami hipertensi berumur 60 tahun.
Terjadinya hipertensi pada lansia dikarenakan oleh kurangnya olahraga, dimana pada orang yang kurang aktivitas akan cenderung mempunyai frekuensi denyut jantung lebih tinggi sehingga otot jantung harus bekerja lebih keras pada tiap kontraksi. Makin keras dan sering otot jantung memompa maka makin besar tekanan yang dibebankan pada arteri. Sebagian besar responden kurang berolahraga karena keadaan fisiknya yang tidak memungkinkan seperti sudah tua dan kesibukan mengurus pekerjaan rumah. Jadi mereka rata-rata tidak mempunyai waktu untuk melakukan olahraga.

\section{Umur}

Berdasarkan tabel 1, dapat disimpukan bahwa mayoritas responden berusia $\geq 50$ tahun dengan jumlah 50 responden $(71,42 \%)$. Usia lansia yang terbanyak dalam kegiatan ini yaitu kategori usia lansia (elderly). Prevalensi hipertensi yang semakin tinggi terjadi pada usia $\geq 50$ tahun disebabkan adanya pengaruh degenerasi, bertambahnya usia akan mempengaruhi sistem fisiologi peredaran darah, terutama pada pembuluh darah. Pradetyawan (2014) menyatakan pengaruh degenerasi 
yang terjadi pada orang yang bertambah usianya akan membuat tekanan darah meningkat.

Setelah usia 45 tahun, dinding arteri akan mengalami penebalan oleh karena adanya penumpukan zat kolagen pada lapisan otot, sehingga pembuluh darah akan berangsurangsur menyempit dan menjadi kaku. Peningkatan usia akan menyebabkan beberapa perubahan fisiologis, pada usia lanjut terjadi peningkatan resistensi perifer dan aktivitas simpatik. Pengaturan tekanan darah yaitu reflek baroreseptor pada usia lanjut sensitivitasnya sudah berkurang, sedangkan peran ginjal juga sudah berkurang dimana aliran darah ginjal dan laju filtrasi glomerulus menurun (Pradetyawan, 2014).

Hasil pengabdian masyarakat ini juga sesuai dengan hasil penelitian Budi (2010) yang menyatakan prevalensi hipertensi pada usia dibawah 40 tahun pada umumnya masih dibawah 10\%, tetapi prevalensi pada usia diatas 50 tahun angka ini mencapai $20 \%$ atau lebih, sehingga merupakan problema yang serius pada golongan usia lanjut.
Pasien yang berusia di atas 60 tahun, 50-60\% mempunyai tekanan darah lebih besar atau sama dengan 140/90 mmHg (Pradetyawan, 2014).

\section{Kurangnya olahraga}

Selain faktor usia, hipertensi juga disebabkan karena kurangnya olahraga. Olahraga merupakan serangkaian gerak raga yang teratur dan terencana untuk memelihara kehidupan, meningkatkan kualitas hidup dan mencapai tingkat kemampuan jasmani yang sesuai dengan tujuan (Giriwoyo dan Sidik, 2012). Kesibukan dalam duniawi yang serba cepat dan serba mesin menyebabkan orang menjadi kurang gerak dan diikuti dengan stres yang dapat mengundang berbagai penyakit kardiovaskuler seperti penyakit jantung, tekanan darah tinggi dan stroke. Hal tersebut banyak dijumpai pada kelompok usia pertengahan, tua dan lanjut, khususnya pada seseorang yang tidak melakukan olahraga (Giriwoyo dan Sidik, 2012).

Seseorang dengan aktivitas
olahraga yang kurang memiliki
pengontrolan nafsu makan yang
sangat labil, sehingga konsumsi


energi menjadi berlebihan. Hal ini mengakibatkan nafsu makan bertambah akhirnya berat badan akan bertambah dan bahkan dapat menyebabkan obesitas. Apabila berat badan seseorang bertambah, maka volume darah juga akan bertambah, sehingga beban jantung untuk memompa darah bertambah pula. Dengan beban yang semakin besar, maka semakin berat kerja jantung dalam hal memompa darah ke seluruh tubuh sehingga tekanan perifer dan curah jantung dapat meningkat kemudian menimbulkan hipertensi (Angraini, 2014).

Dapat dilihat pada tabel 3 . bahwa 70 responden menunjukkan perbedaan nilai tekanan darah lansia dengan hipertensi sebelum dan sesudah olahraga senam pada lanjut usia ini. Nilai tekanan darah sebelum dilakukan olahraga senam pada lansia umumnya lebih tinggi. Lansia yang kurang melakukan aktifitas atau olahraga, pembuluh darah kurang elastis dan diprediksikan banyak tahanan didalamnya. Makin kurang gerakan yang dilakukan semakin mudah seseorang menderita hipertensi ditambah lagi asupan makanan yang kurang terkontrol. Setelah melakukan olahraga senam nilai tekanan darah pada lansia umumnya lebih rendah dari sebelum olahraga. Tekanan darah masyarakat mengalami penurunan setelah melakukan senam hipertensi. Penyebab terjadinya penurunan tekanan darah setelah berolahraga senam lansia adalah hilangnya hambatan atau tahanan dalam kapiler darah sehingga darah dapat mengalir dengan mudah dan lancar dibandingkan dengan sebelum melakakukan olahraga. Senam pada lansia juga membantu meningkatkan kebugaran dan fitalitas tubuh lansia dalam mempertahankan kesehatannya (Widianti, 2010).

Hasil pengabdian masyarakat ini didukung oleh penelitian yang dilakukan oleh Emi Y, M.C. Tonny (2011) dan N. Hosung, T.Kiyoji at el, dimana olahraga pada penderita hipertensi dapat memberi pengaruh bahwa aktivitas fisik dapat menyebabkan seseorang menjadi lebih tenang, kurang menderita ketegangandan kecemasan. Latihan fisik akan membuat seseorang lebih kuat menghadapi stres dan gangguan hidup sehari-hari, lebih dapat 
berkonsentrasi, tidur lebih nyenyak dan merasa berprestasi. Hal ini disebabkan karena gerakan fisik bisa digunakan untuk memproyeksikan ketegangan, sehingga setelah latihan,orang merasa ada beban jiwa yang terbebaskan.

\section{Konsumsi Garam}

Dapat dilihat dari Tabel 4. menunjukkan bahwa dari 70 responden mayoritas mengonsumsi garam secara berlebihan. Makanan asin terbanyak yang dikonsumsi lansia adalah garam atau natrium. Konsumsi garam (natrium) memiliki efek langsung terhadap tekanan darah. Masyarakat yang mengkonsumsi garam yang tinggi dalam pola makannya juga adalah masyarakat dengan tekanan darah yang meningkat seiring bertambahnya usia. Sebaliknya, masyarakat yang konsumsi garamnya rendah menunjukkan hanya mengalami peningkatan tekanan darah yang sedikit, seiring dengan bertambahnya usia (Michael et al., 2014).

Mustamin (2010) menjelaskan bahwa asupan garam (Natrium Chlorida) dapat meningkatkan tekanan darah. Sari, D.M. (2013) menambahkan bahwa asupan tinggi natrium menyebabkan hipertropi sel adiposit akibat proses lipogenik pada jaringan lemak putih, jika berlangsung terus menerus akan menyebabkan penyempitan saluran pembuluh darah oleh lemak dan berakibat pada peningkatan tekanan darah.

\section{a. Penyuluhan Kesehatan}

Pendidikan kesehatan merupakan prioritas utama dan meru-pakan salah satu intervensi keperawatan yang efektif untuk meningkatkan tingkat kesadaran masyarakat akan pentingnya pemahaman yang benar mengenai hipertensi. Namun demikian, efektifitas pendidikan kesehatan belum sepenuhnya diketahui pengaruh pendidikan kesehatan terhadap peningkatan pengetahuan, sikap dan keterampilan keluarga terutama dalam merawat anggota keluarga dengan hipertensi.

Berdasarkan pengabdian masyarakat ditemukan $57,14 \%$ responden yang awalnya sama sekali belum mengenal tentang penyakit hipertensi, akhirnya 
mendapatkan peningkatan pengetahuan setelah dilakukan pendidikan kesehatan dilihat dari respon umpan balik saat tanya jawab dengan penyaji.

Dalam hal ini dapat disimpulkan bahwa terdapat peningkatan pengetahuan masyarakat tentang tindakan non farmakologi untuk menurunkan tekanan darah penderita hipertensi. Hal ini dimungkinkan karena responden dapat memahami materi pendidikan kesehatan yang diberikan dengan metode ceramah, menggunakan media power point, serta leaflet dengan baik.

Hal ini sejalan dengan penelitian sebelumnya (Purwati, et al, 2014) terdapat pengaruh penyuluhan kesehatan terhadap peningkatan pengetahuan klien hipertensi. dengan penelitian sebelumnya (Susanti, et al., 2012) bahwa ada pengaruh yang signifikan antara pemberian pendidikan kesehatan dan sikap baik sebelum dan sesudah diberikan pendidikan kesehatan tentang hipertensi terhadap sikap dalam mengelola hipertensi. Penelitian Beigi, et al., (2014) menunjukkan bahwa program pendidikan efektif dalam meningkatkan pengetahuan, meningkatkan manajemen diri, dan mengendalikan kebiasaan gaya hidup yang merugikan pasien dengan hipertensi. Selain itu, penelitian Ludianita (2013) menunjukkan terdapat interaksi pengaruh pendidikan kesehatan dan sikap terhadap perilaku penderita hipertensi.

\section{b. Kegiatan Senam Hipertensi}

Senam hipertensi merupakan olah raga yang salah satunya bertujuan untuk meningkatkan aliran darah dan pasokan oksigen kedalam otot-otot dan rangka yang aktif khususnya terhadap otot jantung. Mahardani (2010) mengatakan dengan senam atau berolah raga kebutuhan oksigen dalam sel akan meningkat untuk proses pembentukan energi, sehingga terjadi peningkatan denyut jantung, sehingga curah jantung dan isi sekuncup bertambah. Dengan demikian tekanan darah akan meningkat. 
Setelah berisitirahat pembuluh darah akan berdilatasi atau meregang, dan aliran darah akan turun sementara waktu, sekitar 30-120 menit kemudian akan kembali pada tekanan darah sebelum senam. Jika melakukan olahraga secara rutin dan terus menerus, maka penurunan tekanan darah akan berlangsung lebih lama dan pembuluh darah akan lebih elastis. Mekanisnme penurunan tekanan darah setelah berolah raga adalah karena olahraga dapat merilekskan pembuluh-pembuluh darah. Sehingga dengan melebarnya pembuluh darah tekanan darah akan turun.

Dapat dilihat pada tabel 3 . menunjukkan bahwa adanya penurunan tekanan darah setelah melakukan senam hipertensi. Berubahnya tekanan darah pada penderita hipertensi itu sendiri dapat dipengaruhi oleh beberapa faktor, diantaranya adalah faktor dari senam hipertensi itu sendiri. Dimana pada setiap gerakan hipertensi mempunyai fungsi masing-masing, seperti grakan menepuk punggung tangan ini berfungsi melancarkan peredaran darah pada anggota tubuh bagian atas dan gerakan jongkok berdiri ini berfungsi melancarkan sirkulasi darah balik ke jantung serta mencegah aliran darah tersumbat dan sakit jantung.

Menurut Setiawan (2013) belum banyak masyarakat yang tahu tentang terapi senam hipertensi sebagai salah satu cara menurunkan tekanan darah, karena sebagian besar masyarakat memilih menggunakan obat (terapi farmakologi) untuk menurunkan tekanan darah. Penanganan hipertensi dapat dilakukan dengan terapi non farmakologis, salah satunya adalah senam hipertensi. Terapi ini adalah terapi positif yang bertujuan untuk meningkatkan aliran darah dan pasokan oksigen ke dalam otot-otot dan rangka yang aktif khususnya terhadap otot jantung.

Hasil pengabdian masyarakat ini sesuai dengan penelitian Margiyati (2010) yang menyatakan bahwa senam lansia 
dapat menurunkan tekanan darah pada lansia penderita hipertensi. Melakukan gerakan yang tepat selama 30 menit sebanyak 2 kali per minggu, dapat menurunkan tekanan darah sebanyak 10 mmHg pada bacaan sistolik dan diastolic. Olahraga teratur selain dapat mengurangi stress, juga dapat menurunkan berat badan, membakar lebih banyak lemak di dalam darah, dan memperkuat otot-otot jantung (Hernawan, 2017).

\section{c. Demonstrasi Jus Seledri \& Mentimun}

Dapat dilihat pada tabel 3. menunjukkan bahwa responden mengalami penurunan tekanan darah. Salah satu tindakan nonfarmakologi yang dapat dilakukan untuk menurunkan tekanan darah pada penderita hipertensi adalah jus daun seledri dan mentimun.

Menurut analisa, adanya pengaruh pemberian jus mentimun terhadap tekanan darah dikarenakan pada mentimun terdapat kandungan mineral kalium yang merupakan elektrolit intraseluler yang utama. Kalium mempengaruhi aktivitas baik otot skelet maupun otot jantung. Mengkonsumsi mentimun juga dapat menurunkan tekanan darah dan sangat baik untuk penderita hipertensi. Menurut Solanki. P (2011) menyatakan beberapa mekanisme bagaimana kalium dapat menurunkan tekanan darah sebagai berikut : Kalium dapat menurunkan tekanan darah dengan vasodilatasi sehingga menyebabkan penurunan retensi perifer total dan meningkatkan output jantung. Karena mentimun memiliki sekitar $95 \%$ dari kandungan air maka mentimun menurunkan tekanan darah dengan berkhasiat sebagai diuretik. Air mentimun juga berkhasiat menjaga kesehatan ginjal dan aktivitasnya sehingga dapat mengubah aktivitas sistem renin angiotensin. Kandungan kalium membantu mengatur saraf perifer dan sentral yang mempengaruhi tekanan darah. Cara kerja kalium adalah kebalikan dari natrium. Konsumsi kalium yang banyak akan meningkatkan konsentrasinya 
di dalam cairan intraseluler sehingga cenderung menarik cairan dari bagian ekstraseluler dan menurunkan tekanan darah (Amran Y et al, 2010).

Sedangkan untuk daun seledri itu mengandung flevonoid, saponi, tanin $1 \%$ minyak asiri 0,033\%, flavuglukosida (apiin), apigenin, fitosterol, kolin, lipase, pthalides, asparagine, zat pahit, vitamin (A, B dan C), apiinminyak menguap, apigenin dan alkaloid. Kandungan kimia daun seledri secara keseluruhan. Apigenin dalam daun seledri berfungsi sebagai beta blocker yang dapat memperlambat detak jantung dan menurunkan kekuatan kontraksi jantung sehingga aliran darah yang terpompa lebih sedikit dan tekanan darah menjadi berkurang. Manitol dan apiin, bersifat diuretik yaitu membantu ginjal mengeluarkan kelebihan cairan dari dalam tubuh, sehingga berkurangnya cairan dalam darah akan menrunkan tekanan darah. Hal ini sesuai dengan penelitian Sakinah, et al
(2018) dimana berdasarkan hasil penelitian, rebusan daun seledri dapat menurunkan tekanan darah dapat dilihat dari mekanisme umum seledri dalam mengontrol tekanan darah antara lain, memberikan efek dilatasi pada pembuluh darah dan menghambat angiotensin converting enzym (ACE). Penghambat sistem reninangiotensin dapat menurunkan kemampuan ginjal dalam meningkatkan tekanan darah. Tekanan darah mulai turun sehari setelah pengobatan yang diiukti dengan membaiknya tidur terasa nyaman, jumlah urin yang dikeluarkan meningkat.

\section{KESIMPULAN DAN SARAN}

\section{A. KESIMPULAN}

Kegiatan ini banyak memberi manfaat terutama bagi warga yang menderita hipertensi. Harapannya setelah kegiatan ini warga dan kader bekerjasama untuk melakukan senam hipertensi secara rutin dan memanfaatkan bahan-bahan seperti seledri dan mentimun untuk mengontrol tekanan darah 
GEMASSIKA: Jurnal Pengabdian Kepada Masyarakat

Vol. 4 No. 2 November 2020

B. SARAN

Setelah diadakan pengabdian masyarakatinikaderperlumenindaklanjuti untuk tetap mendampingi lansia dan memotivasi lansia agar tetap menjaga kesehatan serta melakukan pengontrolan tekana darah secara rutin.

\section{DAFTAR PUSTAKA}

AHA. 2017. Understanding Blood Pressure Readings. AHA : 1-22.

Amran Y et al. 2010. Pengaruh Tambahan Asupan Kalium dan Diet Terhadap Penurunan Hipertensi Sistolik dan diastolik Tingkat Sedang Pada Lanjut Usia. Penelitian Universitas Islam Syarif hasanudin. Jakarta.

Angraini, R.D. 2014. Hubungan Indeks Massa Tubuh (IMT), Aktivitas Fisik, Rokok, Konsumsi Buah, Sayur dan Kejadian Hipertensi Pada Lansia di Pulau Kalimantan. Skripsi. Jakarta: Universitas Esa Unggul.

Beigi, M.A., et al. 2014. The effect of educational program on hypertension management. International Cardiovascular Research Journal, 8(3) 94-98.

Bell, K., Twiggs, J., Olin, B.R. 2015. Hypertension: The Silent Killer: Updated JNC-8 Guideline Recommendations. Alabama Pharmacy Association.

Bope E T., Rick D. K. 2017. Conn's Current Therapy 2017. Philadelphia: Elsevier Inc.

Darmawan, H., Tamrin, A., \& Nadimin, N. 2018. Hubungan Asupan Natrium dan Status Gizi Terhadap Tingkat Hipertensi Pada Pasien Rawat Jalan Di RSUD Kota Makassar. Media Gizi Pangan, 25(1), 11-17.

Giriwoyo, S. dan D.Z Sidik. 2012. Ilmu Kesehatan Olahraga. Bandung : PT. Remaja Rosdakarya.

Hernawan, Totok dan Nur Rosyid, Fahrun. 2017. Pengaruh Senam Hipertensi Lansia Terhadap Penurunan Tekanan Darah Lansia dengan Hipertensi di Panti Werdha Darma Bhakti Kelurahan Pajang Surakarta. Jurnal Kesehatan. Surakarta : Universitas Muhammadiyah Surakarta. 
Ignatavicius, Workman, \& Rebar.2017. Medical Surgical Nursing: Concepts For Interprofessional Collaborative Care (9 th ed.). St. Louis : Elsevier, Inc.

Irwan. 2016. Epidemiologi Penyakit Tidak Menular. Yogyakarta: Deepublish.

Ludianita, O. 2013. Pengaruh pendidikan kesehatan terhadap perilaku penderita hipertensi ditinjau dari aspek sikap tentang hipertensi di Desa Malasan Kecamatan Durenan Kabupaten Trenggalek. Tesis.

Margiyati. 2010. Pengaruh senam lansia terhadap penurunan tekanan darah pada lansia penderita hipertensi di posyandu lansia ngudi waras, dusun kemloko, desa bergas kidul.

Michael et al. 2014. Tatalaksana Terkini Pada Hipertensi. Jurnal Kedokteran Meditek. 20:52

Pradetyawan. 2014. Hubungan Antara Usia dan Jenis Kelamin dengan Tekanan Darah Tinggi di Posyandi Lansia Desa Triyagan Mojolaban Sukoharjo. [Skripsi Ilmiah]. Surakarta: Universitas Muhammadiyah Surakarta.

Pratiwi, D. P, et al. 2019. Hubungan Pola Konsumsi Seledri (Apium Graveolens L) Terhadap Tekanan Darah Mahasiswa Fakultas Kedokteran Universitas Udayana. E-Jurnal Medika Udayana, 8(4). https://ojs.unud.ac.id/index.php/eum/article/view/50050 Diakses 7 Mei 2020.

Purwati, R.D., et al. 2014. Pengaruh penyuluhan kesehatan terhadap pengetahuan perilaku klien hipertensi di puskesmas bahu manado. Journal Unsrat.

Riskesdas. 2013. Badan penelitian dan pengembangan kesehatan kementerian kesehatan ri. Jakarta.(online).https://kesga.kemkes.go.id/images/pedoman/Data\%20Riskesdas\%20 2013.pdf Diakses 6 Mei 2020.

Riyadi, Sujono. 2011. Keperawatan Medikal Bedah. Yogyakarta: Pustaka Pelajar.

Sakinah, S. Azhari,K.H. 2018. Pengaruh Rebusan Daun Seledri Terhadap Penurunan Tekanan Darah Pada Pasien Hipertensi Di Wilayah Kerja Puskesmas Pangkajene Kabupaten Sidrap. Jurnal Ilmiah Kesehatan Diagnosis Volume 12 Nomor 3 Tahun 2018. eISSN : 2302-2531. 
GEMASSIKA: Jurnal Pengabdian Kepada Masyarakat

Vol. 4 No. 2 November 2020

Setiati, Siti. 2015. Buku Ajar Ilmu Penyakit Dalam Jilid II Ed. VI. Jakarta: Interna Publishing.

Setiawan G.W. 2013. Pengaruh Senam Bugar Lanjut Usia Terhadap Kualitas Hidup Penderita Hipertensi. Manado: Fakultas Kedokteran, Universitas Sam Ratulangi Manado.

Smeltzer, S.C. \& Bare, B.G. 2013. Buku Ajar Keperawatan Medikal Bedah Brunner \& Suddarth. Edisi 8. Jakarta : EGC.

Susanti, M.T., et al. 2012. Pengaruh pendidikan kesehatan tentang hipertensi terhadap pengetahuan dan sikap mengelola hipertensi di puskesmas pandanaran semarang.

Susanti, T.M. Suryani, M. Shobirun. 2012. Pengaruh Pendidikan Kesehatan Tentang Hipertensi Terhadap Pengetahuan Dan Sikap Mengelola Hipertensi Di Puskesmas Pandanaran Semarang.Karya Ilmiah S1 Keperawatan. (online). http://ejournal.stikestelogorejo.ac.id/ index.php/ilmukeperawatan/article/view/66 Diakses 6 Mei 2020.

Triyanto, Endang. 2014. Pelayanan Keperawatan Bagi Penderita Hipertensi Secara Terpadu. Yogyakarta: Graha Ilmu.

WHO. 2013. World Health Day 2013: Measure Your Blood Pressure, Reduce Your Risk.

Wibowo, A.M. 2010. Pengaruh Pemberian Jus Mentimun Terhadap Penurunan Tekanan Darah Sistolik dan Diastolik penderita Hipertensi Esensial Pada Lansia di PSTW Budi Luhur Yogyakarta. Yogyakarta. Skripsi. http://digilib.unisayogya.ac.id/1766/ Diakses 7 Mei 2020.

Widianti. A.T. dan Proverawati, A. 2010. Senam dan Kesehatan. Yogyakarta : Nuha Medika.

Black,J.M. \& Hawks,J.H. 2014. Keperawatan Medikal Bedah. Jakarta:Elsevier.

Nursalam \& Efendi, F. 2008. Pendidikan Dalam Keperawatan. Jakarta : Salemba Medika.

Suidah, H., \& Ns, S. K. 2011. Pengaruh Mengkudu Terhadap Penurunan Tekanan Darah pada Penderita Hipertensi di Desa Wedoroklurak Kecamatan Candi Kabupaten Sidoarjo. Jurnal Keperawatan, 1(1).

154 Senam Hipertensi dan Demonstrasi... 